\title{
Caracterização do Xote e do Baião dançados no interior do Estado de São Paulo
}

\author{
Antonio Carlos de Quadros Junior* \\ Ellen Cristina Fontes** \\ Romualdo Dias ${ }^{* * *}$ \\ Catia Mary Volp ${ }^{* * * *}$
}

\begin{abstract}
Resumo: A Dança de Salão e o Forró fazem parte da cultura brasileira, e o Xote e o Baião fazem parte do Forró. O objetivo deste estudo foi diagramar as danças Xote e Baião no interior do Estado de São Paulo e descrever ritmicamente seus movimentos. Foram observados e filmados diversos casais universitários dançando Xote e Baião para análise e descrição discursiva e por meio de diagramas dos movimentos das danças. Identificam-se duas estruturas básicas que denominamse "Passo Básico Lateral" e "Passo Básico Frente e Trás", e as variações "Abertura" e "Troca de Lugar com Giro", muito utilizadas pelos casais.
\end{abstract}

Palavras-chave: Dança. Folclore. Música. Cultura. Diagramação.

\section{INTRODUÇão}

No Estado de São Paulo, o Xote e o Baião são as constituintes do Forró mais difundidas. Em relação às origens, por volta de 1850, o Schottisch veio dos salões europeus para as regiões rurais brasileiras e passou a ser chamado de Xote (GIFFONI, 2003; LELLIS, 1998b).

\footnotetext{
* Mestre em Ciências da Motricidade. Laboratório de Atividade Física e Envelhecimento e Laboratório de Comunicação Corporal, Expressão e Música - Departamento de Educação Física - Universidade Estadual Paulista (UNESP) Rio Claro, SP, Brasil. Professor de Dança de Salão. E-mail: jrinhobru@yahoo.com.br

** Graduada em Licenciatura em Educação Física. Laboratório de Comunicação Corporal, Expressão e Música. UNESP - Rio Claro, SP. Professora de Dança de Salão. Rio Claro, SP, Brasil. E-mail: ell_cris10@hotmail.com

*** Formado em Filosofia e Pedagogia. Professor assistente doutor. Departamento de Educação. UNESP - Rio Claro, SP, Brasil. E-mail: diasro@uol.com.br

**** Livre-docente em Atividades rítmicas e dança. Professora assistente doutor. UNESP - Rio Claro, SP, Brasil. E-mail: cmvolp@rc.unesp.br
} 


\section{Antifos Orifimais Antonio Carlos de Quadros Junior et al.}

O Baião teve sua origem no século XIX, no nordeste do país, mas não há mais exatidão sobre seu surgimento, e sua popularização se deu a partir da década 1940, com as músicas de Luís Gonzaga (MEDINA, 1998; SILVA, 2003). Apesar da mesma estrutura de passos, as danças Xote e Baião diferem entre si quando seguem os respectivos gêneros musicais. Ambas são binárias, mas transmitem sensações diferentes, devido às diferenças quanto ao ritmo e à velocidade. $^{1}$

Sobre o termo "Forró" há muitas controvérsias, diferentes significados, pois a palavra pode referir-se a uma festa (JACINTO, 2001; LELLIS, 1998a; ROCHA, 2004; TRINDADE, 2004), a um gênero musical (GIFFONI, 2003; TRINDADE, 2004), a um local (ROCHA, $2004)$ etc. Entende-se que o termo Forró designa a festa em que se dança e se tocam gêneros musicais nordestinos (QUADROS JR; VOLP, 1995), e que nele há reunião social com dança aos pares, o que caracteriza a Dança de Salão (DS) (SILVESTER, 1990; VOLP, 1994). Tais gêneros são xote, baião, xaxado, côco de roda, marcha de roda, entre outros (JACINTO, 2001; ROCHA, 2004).

Na DS, os pares de dançarinos sincronizam passos e figuras, ao som de música, mantendo-se dentro das normas sociais em relação ao contato entre eles e com os outros pares no salão (VOLP, 1994). Mas ainda há a necessidade da interação harmoniosa entre os parceiros para sua prática satisfatória. A DS nada mais é do que o próprio andar, com algumas características peculiares; não basta seguir o ritmo, deve-se buscar elegância, postura, delicadeza.

A importância do estudo das DS e de sua cultura pode ser apreciada em Rust (1969), quando a autora afirma que a sociedade é que acompanha a dança, e não o contrário. No momento em que efetivamente há a mudança (uma nova dança, com uma nova postura, mais ousada, ou a aceitação social desta nova postura) é a dança que impõe à sociedade a aceitação desta. Surge, pois, a preocupação com a cultura brasileira e suas danças. É necessário caracterizar as danças componentes do Forró, no caso o Xote e o Baião,

\footnotetext{
${ }^{1}$ Para mais detalhes sobre gênero, estilo e ritmo musicais, ver Quadros Jr; Volp, 2005.

Movimento, Porto Alegre, v. 15, n. 03, p. 233-247, julho/setembro de 2009.
} 
para entender-se sua dinâmica, quais influências sofrem e quais causam. Interessa conhecer não somente as estruturas dos passos das danças que compõem o Forró, mas também todo o movimento cultural que o faz e aquele que ele cria. Segundo Betti (1992), é indissociável a relação entre cultura, corpo e movimento, a qual torna necessário aprofundar o conhecimento cultural de uma expressão corporal, no caso o Forró, por meio das danças Xote e Baião.

A justificativa deste estudo se dá pela necessidade de: a) melhor entendimento do fenômeno cultural brasileiro denominado Forró; e b) diagramação e/ou catalogação das danças, uma vez que ainda não se preencheu tal lacuna.

O objetivo deste estudo foi caracterizar o Xote e o Baião dançados no interior do Estado de São Paulo, verificando os passos mais utilizados, descrevendo-os ritmicamente e analisando culturalmente o Forró.

\section{MATERIAL E MÉTODO}

\subsection{Participantes}

Foram estudadas três amostras. Na primeira amostra, foram observados 50 casais dançando Xote e Baião, em festas universitárias nas cidades de Bauru, Rio Claro e São Carlos. Esses municípios possuem grandes comunidades universitárias que dançam o Forró, o que parece permitir ampliar a caracterização para o interior do Estado de São Paulo. Todos eram estudantes universitários da Universidade Estadual Paulista (UNESP), campi Bauru e Rio Claro, da Universidade Federal de São Carlos, e da Universidade de São Paulo, ambas em São Carlos, com média de idade de 22 anos. Os jovens dançavam frequentemente Xote e Baião. Destes, foram selecionados, aleatoriamente, cinco casais para filmagem, para posterior análise e descrição dos movimentos fundamentais das danças. Na segunda amostra, foram entrevistados seis dançarinos universitários "forrozeiros" da UNESP - Rio Claro, sendo quatro do sexo masculino e dois do sexo feminino, com média de idade de 24 anos. Todos dançam frequentemente

Movimento, Porto Alegre, v. 15, n. 03, p. 233-247, julho/setembro de 2009. 


\section{Antifos Orifimais Antonio Carlos de Quadros Junior et al.}

Xote e Baião e são cultuadores da cultura forrozeira. Na terceira amostra, foram consultados, no início da pesquisa, seis músicos profissionais (músicos e professores de música que já tiveram contato profissional com o Forró, com média de idade de 31 anos), de renome nacional, porém, somente dois responderam efetivamente ao questionário enviado. O Comitê de Ética em Pesquisa da UNESP - Rio Claro aprovou o projeto de pesquisa e todos os participantes assinaram o Termo de Consentimento Livre e Esclarecido.

\subsection{Instrumentos}

Realizaram-se, para a coleta de dados da primeira amostra, observação in loco e posterior filmagem no Laboratório de Comunicação Corporal, Expressão e Música, do Departamento de Educação Física da UNESP - Rio Claro. Com a segunda amostra, realizou-se uma entrevista. Num local à escolha do entrevistado, o entrevistador gravava a conversa, seguindo um pequeno roteiro com perguntas sobre o Forró. Para a terceira amostra, utilizou-se um questionário de autoria própria para a coleta dos dados, enviado e respondido por e-mail.

\subsection{Materiais}

A filmagem foi realizada com uma filmadora JVC GR-AX800U, com a música executada por um aparelho de som AIWA NSX-S305. A análise da gravação foi feita com a utilização de TV Sharp C2010B e videocassete Panasonic NV-SJ405. As entrevistas foram gravadas em microgravador Panasonic RN-102, transcritas com a utilização de computador PC. Os questionários foram enviados aos participantes utilizando o mesmo computador.

\subsection{Procedimentos}

Para coleta da primeira amostra, foram realizadas: a) observações in loco; b) filmagem dos casais selecionados; e c) análise da filmagem e descrição dos passos. O procedimento para a coleta da segunda amostra foi: a) gravação da entrevista; b) transcrição da entrevista; e c) análise das respostas. O procedimento para a coleta da terceira amostra foi: a) envio do questionário via e-mail; e b) análise das respostas.

Movimento, Porto Alegre, v. 15, n. 03, p. 233-247, julho/setembro de 2009. 


\subsection{Análise dos Dados}

Para a análise da filmagem e descrição dos movimentos, reproduzia-se a fita por aproximadamente dois segundos, pausava-a e descreviam-se os movimentos executados. A análise das entrevistas foi feita por meio da leitura das transcrições buscando destacar as respostas em comum para a construção de um discurso único. A análise dos questionários, semelhantemente, buscou reconhecer os conteúdos similares. Todas as análises realizadas no estudo foram qualitativas.

\section{RESULTADOS E DISCUSSÃO}

Os resultados e a discussão serão apresentados sem a distinção feita de primeira, segunda ou terceira amostra em Material e Método, pois houve grande interação entre os resultados coletados das três amostras.

\subsection{Diagramas dos Passos}

Abaixo, apresenta-se a legenda para os diagramas (Quadro 1). As descrições são dos passos do Cavalheiro; a Dama realiza movimentos espelhados, conforme mostrado nos diagramas. É importante frisar que somente no passo 4 do Passo Básico Lateral não haverá transferência do peso corporal.

\section{- Pé Dama E Perna Esquerda \\ D Perna Direita \\ - Pé Cavalheiro \\ Esq Direçāo Esquerda \\ PI Posição Inicial Dir Direşâo Diretta}

Figura 1. Legendas dos diagramas.

Movimento, Porto Alegre, v. 15, n. 03, p. 233-247, julho/setembro de 2009. 


\section{Antigor Orifinais Antonio Carlos de Quadros Junior et al.}

A postura do Xote e do Baião pede pés intercalados (conforme Figura 1) e os dois corpos bem unidos, havendo contato pelos quadris e troncos, principalmente na região abdominal. Em relação às mãos, há muita liberdade. A Mão Direita do Cavalheiro (MDC) preferencialmente permanece nas costas da Dama. A Mão Esquerda do Cavalheiro (MEC) pode ficar na altura dos olhos da Dama, ou mais abaixo, ou, ainda, permanecer o braço estendido ao longo do corpo, na lateral da coxa, com a MEC unida à Mão Direita da Dama (MDD). Quanto à Dama, a MDD acompanha a MEC, enquanto que sua Mão Esquerda preferencialmente fica no ombro direito do Cavalheiro. Permanece ainda da técnica da DS o fato de cada um sustentar seu próprio corpo, principalmente a Dama (RIED, 2003; SILVESTER, 1990; VOLP, 1994).

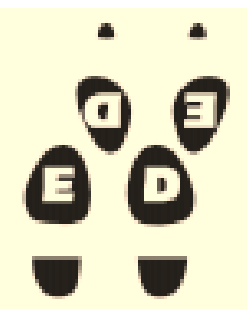

Figura 2. Posição inicial.

Quanto à posição relativa dos troncos, o casal não se coloca em paralelo um em relação ao outro; o que há é uma "intenção de paralelismo", em que o contato abdominal tende a ser lateral, e não frontal, permanecendo, assim, o tronco do cavalheiro, em seu lado direito, em contato com o lado esquerdo do tronco da dama. Deste modo, os troncos do casal seriam duas retas, e o lado direito do tronco do cavalheiro e o lado esquerdo do tronco da dama formariam o vértice de um ângulo, ou seja, conforme as retas seguem afastando-se do vértice, a distância entre elas aumenta.

Com relação à observação realizada das danças Xote e Baião, tem-se os dois passos considerados básicos e duas variações. Neste estudo, procura-se nomear os passos de acordo com o que se faz. Adota-se esta prática pelo fato de haver vários nomes para o mesmo passo.

Movimento, Porto Alegre, v. 15, n. 03, p. 233-247, julho/setembro de 2009. 


\subsection{Diagrama do Passo Básico Lateral (PBL) - Figura 02}

Este é um dos dois passos básicos do Xote e do Baião, também comumente denominado " $2 \times 2$ ", pois o casal desloca dois passos para um lado e retorna dois passos para o outro. No Passo Básico Lateral (PBL), o casal marca os tempos da música, em oito passos, a princípio, no lugar (ou seja, sem deslocamento final). O PBL utilizase de dois compassos: um para os passos 1 a 4; outro para os passos 5 a 8. Assim, desloca-se à Dir (ou à Esq) durante o primeiro compasso, e desloca-se à Esq (ou à Dir), durante o segundo.

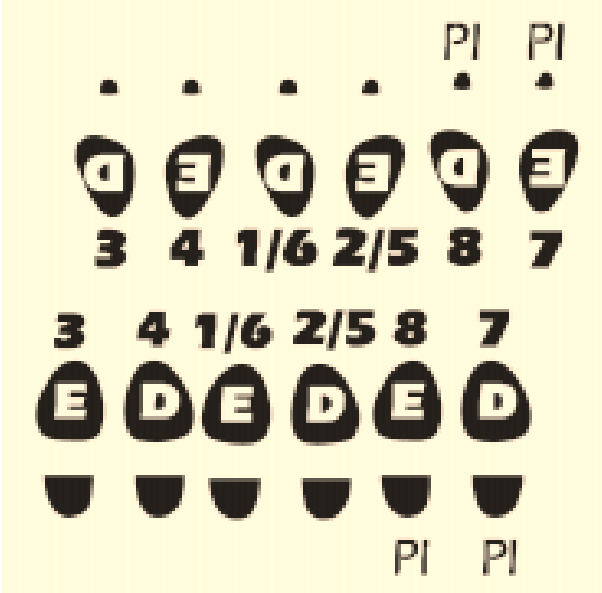

Figura 3. Diagrama do Passo Básico Lateral (PBL).

No passo 1, move-se a E à Esq (passo 1 realizado no tempo 1 do primeiro compasso); no passo 2, une-se a $\mathrm{D}$ à $\mathrm{E}$ (entre os tempos 1 e 2 do primeiro compasso); no passo 3, move-se a E à Esq (tempo 2 do primeiro compasso); no passo 4, une-se a $\mathrm{D}$ à E, sem transferência de peso (entre o tempo 2 do primeiro compasso e o tempo 1 do segundo compasso). No passo 5, move-se a D à Dir (tempo 1 do segundo compasso); no passo 6, une-se a $\mathrm{E}$ à $\mathrm{D}$ (entre os tempos 1 e 2 do segundo compasso); no passo 7, move-se a D à Dir (tempo 2 do segundo compasso); no passo 8, une-se a $\mathrm{E}$ à $\mathrm{D}$, sem transferência de peso (entre o tempo 2 do segundo compasso e o tempo 1 do terceiro compasso).

Movimento, Porto Alegre, v. 15, n. 03, p. 233-247, julho/setembro de 2009. 


\section{Antifos Orifimais Antonio Carlos de Quadros Junior et al.}

\subsection{Diagrama do Passo Básico Frente e Trás (PB F/T) -}

Figura 03

Neste segundo passo básico, ao invés de mover-se para as laterais, move-se para frente e para trás. Nota-se que, após pisar à frente e atrás, não se une os pés no centro.

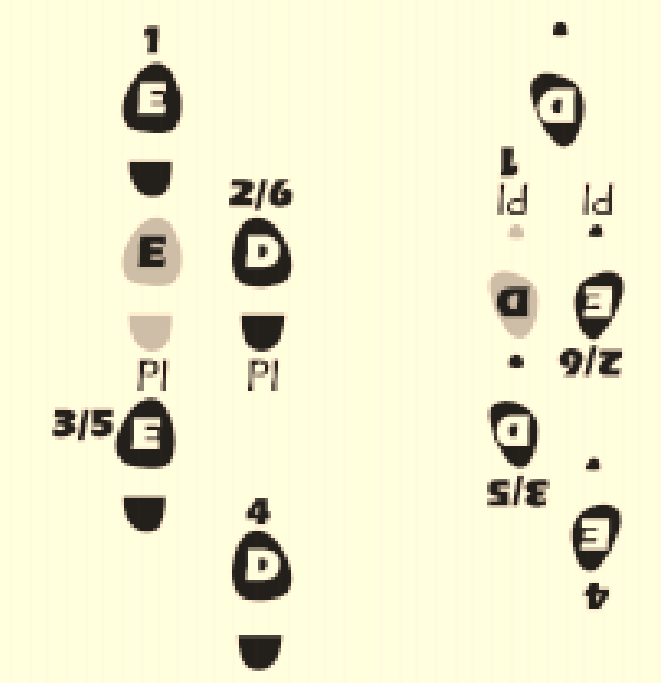

Figura 4. Diagrama do Passo Básico Frente e Trás (PB F/T).

No passo 1, move-se a $\mathrm{E}$ à frente (tempo 1 do primeiro compasso); no passo 2, retorna-se o peso à $\mathrm{D}$ (entre os tempos 1 e 2 do primeiro compasso); no passo 3, move-se a E para trás (tempo 2 do primeiro compasso). No passo 4 , move-se a $\mathrm{D}$ para trás (tempo 1 do segundo compasso); no passo 5, retorna-se o peso à $\mathrm{E}$ (entre os tempos 1 e 2 do segundo compasso); no passo 6, move-se a D para frente (tempo 2 do segundo compasso).

No Forró, há muita liberdade quanto à execução dos passos. Especificamente os dois passos básicos, não precisam necessariamente ser dançados como descritos. Eles podem, por exemplo, serem dançados girando no lugar. As execuções descritas são as maneiras básicas, as mais fáceis para os iniciantes.

Movimento, Porto Alegre, v. 15, n. 03, p. 233-247, julho/setembro de 2009. 


\subsection{Diagrama da Abertura - Figura 04}

O nome Abertura se dá pelo fato de o casal, ao realizar o passo, abrir, ou seja, não manter mais a postura fechada dos PBL e PB F/T. O contato do casal se dá somente pelas mãos: mão D/E do Cav segurando mão E/D da Dama. Assim, o passo tem dois momentos: o de "abrir" (ficando o casal parcialmente virado para o mesmo lado) e o de "fechar" (tornando o casal a ficar um de frente para o outro). Este passo é tido como a principal variação do Xote e do Baião, por ser a base para todas as outras variações, além de também ser, por vezes, um ponto de ligação entre duas variações. Ao reparar-se estruturalmente as variações (como a Troca de Lugar com Giro - descrita abaixo), pode-se perceber que o casal está realizando a Abertura, mas ao invés de "fechar" a perna ao lado da outra, o dançarino movimenta a perna para frente.

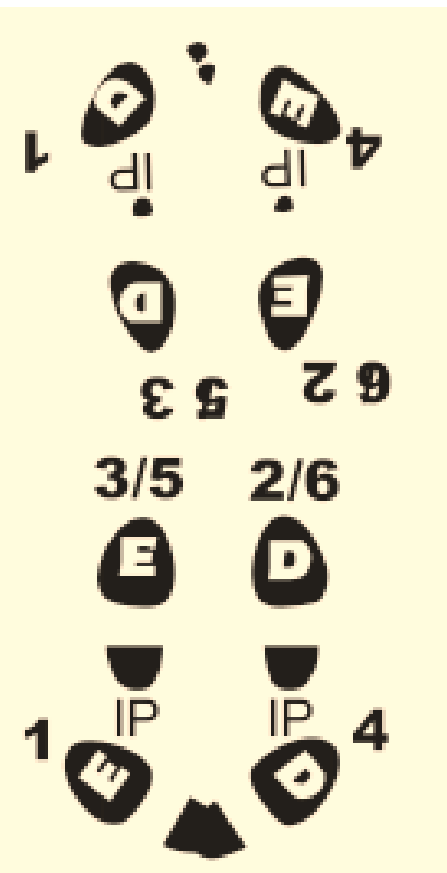

Figura 5. Diagrama da Abertura.

Movimento, Porto Alegre, v. 15, n. 03, p. 233-247, julho/setembro de 2009. 


\section{Antifos Orifimais Antonio Carlos de Quadros Junior et al.}

No passo 1, move-se a E para trás, girando o corpo $1 / 4$ à Esq (tempo 1 do primeiro compasso); no passo 2 , retorna-se o peso à $\mathrm{D}$ (entre os tempos 1 e 2 do primeiro compasso); no passo 3, volta a $\mathrm{E}$ para a posição inicial, paralelo e ao lado da $\mathrm{D}$ (tempo 2 do primeiro compasso). No passo 4, move-se a D para trás, girando o corpo $1 / 4$ à Dir (tempo 1 do segundo compasso); no passo 5, retorna-se o peso à $\mathrm{E}$ (entre os tempos 1 e 2 do segundo compasso); no passo 6, volta a D para a posição inicial, paralelo e ao lado da $\mathrm{E}$ (tempo 2 do segundo compasso).

\subsection{Diagrama da Troca de Lugar com Giro - Figura 05}

Esta variação foi percebida como sendo uma das mais realizadas no Xote e no Baião. Enquanto a Dama troca de lugar girando, o Cav apenas troca de lugar com ela; na sequência, ela apenas troca de lugar, enquanto ele troca de lugar girando. Vale frisar que somente quem está fazendo a Abertura com o PD é quem trocará de lugar girando.

Para a Dama girar, o Cav levanta seu braço E e a conduz com a palma da mão para a troca de lugar com giro. A execução completa deste passo requer apenas 4 tempos musicais.

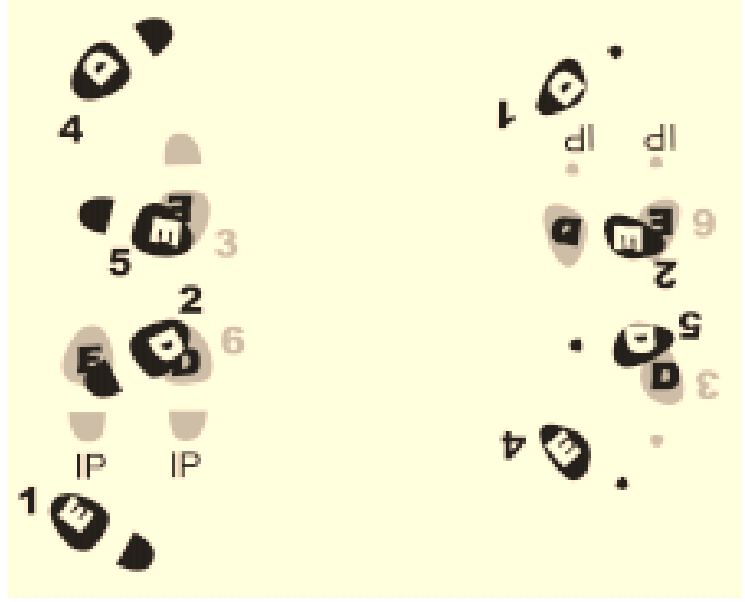

Figura 6. Diagrama da Troca de Lugar com Giro.

Movimento, Porto Alegre, v. 15, n. 03, p. 233-247, julho/setembro de 2009. 
Ele realiza a Abertura com o PE (1) executa o pivô com o PD (2), e pisa com o PE à frente (3). Então, realiza a Abertura com o PD (4), executa o pivô com o PE (5), e pisa com o PD à frente (6).

No passo 1, realiza-se a Abertura com o PE (tempo 1 do primeiro compasso); no passo 2, retorna-se o peso à $\mathrm{D}$, realizando um pequeno giro com o pé, em pivot (entre os tempos 1 e 2 do primeiro compasso); no passo 3, movimenta-se a E para a frente, realizando $1 / 4$ de giro no sentido inicial (tempo 2 do primeiro compasso). No passo 4, realiza-se a Abertura com o PD (tempo 1 do segundo compasso); no passo 5, retorna-se o peso à E, realizando um giro com o pé, em pivot, isto é, o giro propriamente dito (entre os tempos 1 e 2 do segundo compasso); no passo 6, movimenta a $\mathrm{D}$ para a frente, realizando mais $1 / 4$ de giro, finalizando a variação (tempo 2 do segundo compasso).

É importante que exista uma efetiva troca de lugar entre o Cav e a Dama, mesmo não sendo necessário girar $180^{\circ}$, como mostrado no diagrama. Quando esta troca de lugar não ocorre corretamente, o dançarino que está realizando o giro é sobrecarregado, porque ele terá que girar mais que o necessário. Quando o movimento é executado corretamente, o dançarino que não está girando deve "fechar" atrás de sua parceria, de frente para as costas dela.

Essa variação é chave para praticamente todos os outros giros. O que irá mudar deste para os outros giros será, basicamente, a relação de mãos entre Cav e Dama. Em outras palavras, ao invés do Cav conduzir a Dama com sua ME, segurando a MD dela, ele irá, por exemplo, conduzi-la para o giro com sua MD, segurando a MD dela ou mesmo a ME, apesar desta última ser incomum nestas danças.

\subsection{Análise das entrevistas e dos questionários}

Pelas entrevistas e questionários, percebe-se que ocorre um mau uso dos termos "gênero musical", "ritmo musical" e "estilo musical", em relação ao que é mostrado em (QUADROS JR; VOLP, 2003). Os participantes foram unânimes ao afirmarem que, no dia a dia, os três termos são usados como sinônimos, tendo o mesmo significado de "gênero musical" na maioria das vezes. A grande maioria

Movimento, Porto Alegre, v. 15, n. 03, p. 233-247, julho/setembro de 2009. 


\section{Antifos Orifinais Antonio Carlos de Quadros Junior et al.}

dos participantes afirmou que Forró é a festa em que se toca xote, baião, xaxado, côco, quadrilha, embolada, maxixe, entre outros. Estes ritmos são diferenciados pela acentuação rítmica.

Das entrevistas, extraímos que o Forró promove um vigor muito grande a quem dança, podendo ser uma alternativa para extravasar o estresse e os sentimentos negativos. Segundo os dançarinos, todo gênero musical constituinte do Forró incita as pessoas a dançarem.

O Xote, por ser estruturalmente diferente e mais lento que o Baião, proporciona uma dança mais calma, em que reina o chamego, a sedução, a conquista; é uma dança mais "no chão", mais "arrastada", usando as gírias dos forrozeiros. Com o Baião acontece o contrário, uma vez que a música é mais rápida, e que a sua estrutura musical dá a intenção de um movimento mais "forte", mais "marcado", mais "vivo", mais "saltitante"; a dança "saltada" faz nascer a vontade de executar os "floreios", que são as variações.

Os dançarinos entrevistados foram escolhidos por serem "cultuadores do Forró" e não simplesmente "praticantes das danças Xote e Baião". Eles apreciam, vivem e divulgam, de certa maneira, a simplicidade pregada pelo próprio Forró, por meio de Luis Gonzaga, Jackson do Pandeiro, entre outros. Ou seja, no dia a dia, eles não simplesmente dançam e/ou tocam Forró, mas vivem o Forró, com suas vestimentas e características próprias, sempre buscando as raízes desta cultura. Em outras palavras, eles fogem do modismo do Forró Universitário, sempre ouvindo/dançando/divulgando os músicos pioneiros dessa manifestação cultural.

De acordo com os dançarinos e a literatura, no Forró está incorporada a simplicidade, a humildade (JACINTO, 2001; NÓBREGA, 2004; ROCHA, 2004), o que torna interessante o fato das classes sociais mais altas terem tomado tanto gosto por ele. Ainda relataram que há uma crescente valorização nacional, que pode ser observada, por exemplo, pela crescente aceitação do Forró no meio universitário.

Apesar das entrevistas, dos questionários e da revisão de bibliografia, não foi possível identificar todos os gêneros musicais que compõem o Forró, nem se existe efetivamente o gênero musical

Movimento, Porto Alegre, v. 15, n. 03, p. 233-247, julho/setembro de 2009. 
denominado Forró, como é afirmado em (GIFFONI, 2003). Isto, pois ainda não há consenso, uma vez que tal assunto não foi devidamente estudado e/ou por ser o Forró um fenômeno muito amplo.

Há uma variação muito grande de gêneros musicais citados como constituintes do Forró. Segundo Rocha (2004, p. 63) no Forró há "[...] o xote, o baião e o xaxado, além de outras" expressões musicais. Para Jacinto (2001), há xaxado, côco de roda, marcha de roda, baião e xote. Mas em todas as relações de gêneros que animam o Forró sempre estão presentes o Xote e o Baião. Como afirma Jacinto (2001, faixa 4), "Forró é simplicidade, é poeira, sanfona, zabumba, triângulo...uma seqüência de ritmos nordestinos: xaxado, côco de roda, marcha de roda, baião, xote... esses ritmos e outros ritmos que agora no momento eu não lembro... isso é que significa forró".

\section{CONSIDERAÇÕES FINAIS}

Por meio das ferramentas de observação e coleta de dados, além da experiência em dança e aulas de Forró e do ambiente universitário, pode-se concluir que o Forró é uma festa, em que se toca e se dança diversos gêneros musicais. É consensual que o Xote e o Baião são os constituintes do Forró mais recorrentes no interior do Estado de São Paulo. O Xote é uma dança mais calma, em que reina a sedução, enquanto o Baião, mais agitado, é mais animado. Os passos fundamentais dessas danças foram os denominados: Passo Básico Lateral, Passo Básico Frente e Trás, Abertura e Troca de Lugar com Giro. É consenso também que no Forró deve reinar a simplicidade e a humildade, características vividas e divulgadas por seus criadores e propagadores principais e também por seus atuais cultuadores.

Movimento, Porto Alegre, v. 15, n. 03, p. 233-247, julho/setembro de 2009. 


\section{Antigor Orifinais Antonio Carlos de Quadros Junior et al.}

Characterization of the Xote and Baião danced
inside the São Paulo State
Abstract: Ballroom dance and Forró are part of
Brazilian culture, and Xote and Baião are part of Forró.
The aim of this study was to diagramate the dances
Xote and Baião they are danced inside São Paulo
State and to describe rhythmly these movements. It
was observed and filmed several college couples
dancing Xote and Baião for analysis and description
of the movements of the dances, by a discursive way
and by diagrams. It was identified two basic structures
(“Lateral Basic Step" and "Forward and Back Basic
Step"), and variation steps "Open" and "Change of
places with Turn", very used by couples.
Keywords: Dancing. Folklore. Music. Culture.
Diagram.

Caracterización del Xote y del Baião bailados dentro del estado de São Paulo

Resumen: Baile de salón y Forró hacen parte de la cultura brasileña, y Xote y Baião, del Forró. El propósito de este estudio fue diagramar las danzas Xote y Baião bailados dentro del estado de São Paulo y describir rítmicamente los movimientos de las mismas. Para el análisis y la descripción de movimientos de Xote y Baião, de manera discursiva y con los diagramas, fueron observadas y filmadas varias parejas universitarias bailando dichas danzas. Fueron identificados "paso básico lateral" y "paso básico adelante y atrás", y las variaciones "abertura" y "cambio de lugar con giro", muy usadas por las parejas.

Palabras clave: Baile. Folclor. Música. Cultura. Diagrama.

\section{REFERÊNCIAS}

BETTI, M. Ensino de primeiro e segundo graus: educação física para quê? Revista Brasileira de Ciências do Esporte, Porto Alegre, v. 13, n. 2, p. 282-287, 1992.

GIFFONI, A. Forró. Cover Baixo, São Paulo, v. 1, n. 9, p. 51, 2003.

GIFFONI, M. A. Danças folclóricas da Europa. São Paulo: Melhoramentos/EDUSP, 1974.

JACINTO, S. Puxe o fole Zé. In: PESSOA, S. Bate o mancá: o povo dos canaviais. [S.I.]: Natasha Recordes, 1 CD. Faixa 4, 2001.

Movimento, Porto Alegre, v. 15, n. 03, p. 233-247, julho/setembro de 2009. 
LELLIS, L. Levadas para forró. Batera, São Paulo, v. 2, n. 18, p. 57, 1998a.

LELLIS, L. Levadas para xote. Batera, São Paulo, v. 2, n. 16, p. 57, 1998b.

MEDINA, L. Luiz Gonzaga. Drummer, São Paulo, v. 2, n. 23, p. 94-95, 1998.

NÓBREGA, A. Brincadeira muito séria. Caros Amigos, São Paulo, v. 11, n. 82, p. 32-37, jan, 2004.

QUADROS, A. C. Jr.; VOLP, C. M. Forró Universitário: a tradução do forró nordestino no sudeste brasileiro. Motriz, Rio Claro, v. 11, n. 1, p. 117-120, 2005.

RIED, B. Fundamentos de Dança de Salão: programa internacional de dança de salão; dança de salão internacional. Londrina: Midiograf, 2003.

ROCHA, J. M. T. Forró eletrônico, forró universitário. In: FESTIVAL DO FOLCLORE, 40, 2004. Anuário..., Olímpia, v. 34, p. 62-71, ago. 2004.

RUST, F. Dance in society: an analysis of the relationship between the social dance and society in England from the Middle Ages to the Present Day. London: Routledge \& Kegan Paul, 1969.

SILVA, E. L. Forró no asfalto: mercado e identidade sociocultural. São Paulo: Annablume: FAPESP, 2003.

SILVESTER, V. Modern ballroom dancing. London: Stanlley Paul, 1990.

TRINDADE, M. Isso aqui tá bom demais: festas populares que reúnem milhões de pessoas, vendas milionárias de discos e ciclo de shows demonstram o vigor do forró, um gênero que atravessa gerações. Bravo!, São Paulo, v. 7, n. 81, p. 52-57, jun, 2004

VOLP, C. M. Vivenciando a dança de salão na escola. 1994. 276 f. Tese (Doutorado) - Instituto de Psicologia, USP, São Paulo, 1994.

Agradecimentos: Leonídio Barbosa de Quadros, por meio da Leureka! (leoeurekabauru@yahoo.com.br), pela arte dos diagramas; Capes, pela bolsa de mestrado.

Estudo parcialmente apresentado no IV Congresso Internacional de Educação Física e Motricidade Humana e X Simpósio Paulista de Educação Física, Rio Claro.

Recebido em: 09/05/2007

Aprovado em: 03/06/2009

Movimento, Porto Alegre, v. 15, n. 03, p. 233-247, julho/setembro de 2009. 